\title{
Association of hyperlipidaemia in preterm delivery
}

\author{
Ruthvika Kundoor ${ }^{1 *}$, Burri Sandhya Rani ${ }^{2}$
}

${ }^{1}$ Department of Obstetrics and Gynecology, Osmania University, Hyderabad, Telangana, India
${ }^{2}$ Department of Obstetrics and Gynecology, Laxmi Narasimha Hospital, Hanumakonda, Warangal, Telangana, India

Received: 12 February 2019

Accepted: 07 March 2019

\section{*Correspondence:}

Dr. Ruthvika Kundoor,

E-mail: ruthvikakundoor@gmail.com

Copyright: (C) the author(s), publisher and licensee Medip Academy. This is an open-access article distributed under the terms of the Creative Commons Attribution Non-Commercial License, which permits unrestricted non-commercial use, distribution, and reproduction in any medium, provided the original work is properly cited.

\begin{abstract}
Background: Premature infant is the most important outcome of preterm delivery and is also the cause for infant mortality after congenital abnormality. Around the world, there are 3.6 million per year neonatal deaths, of which in developing countries, $99 \%$ deaths are observed. This study was conducted to evaluate the elevated triglycerides and cholesterol relationship on preterm labor risk.

Methods: 350 healthy pregnant women were included in the study group in the age group of 18-36 years, their gestational age was confirmed either by last menstrual period or by ultrasound. This study was conducted in Department of Obstetrics and Gynaecology at Osmania University, Hyderabad, Telangana India.

Results: The good outcomes were observed in mothers with normal cholesterol values and preterm deliveries were observed in $32.14 \%$ of mothers with abnormal cholesterol values. $0.3 \%$ of mothers with normal triglyceride values and $75 \%$ of mothers with abnormal values had preterm delivery. $\mathrm{P}$ value difference was statistically significant $(\mathrm{P}<0.05)$.

Conclusions: By measuring serum total cholesterol and triglycerides, along with serum screening of $\alpha$-fetoprotein and inhibin $\mathrm{A}$, it can be used to predict the preterm labour.
\end{abstract}

Keywords: Cholesterol, Preterm Labour, Hyperlipidemia

\section{INTRODUCTION}

Preterm is defined as babies born alive before 37 weeks of pregnancy are completed. There are sub-categories of preterm birth, based on gestational age namely extremely preterm (less than 28 weeks), very preterm (28 to 32 weeks) and moderate to late preterm (32 to 37 weeks). Induction or caesarean birth should not be planned before 39 completed weeks unless medically indicated. ${ }^{1}$

It occurs before 37 completed weeks of gestation from the day of last menstrual period and is painful, frequent, contractions of uterine which causes progressive dilatation of the cervix. A gestational rise in blood triglycerides and cholesterol is observed in physiological hypertriglyceridemia. Enhanced accumulation of maternal fat is presumed to be important for hypertriglyceridemia which occurs in later gestation. ${ }^{2}$ With gestational age increasing, the circulatory concentrations of VLDL and LDL also increase, and it is reflected by increase in serum TGL and cholesterol markedly. The enhanced entry of triglyceride rich lipoproteins into the circulation is the main cause of hypertriglyceridemia. ${ }^{3}$

In human pregnancy, estrogen plays a pivotal role in patterns of lipoprotein even though LDL cholesterol is more due to combined effect of enhanced estrogen and progesterone. ${ }^{4}$ As term approaches, placental lipoprotein lipase is enhanced additionally. During pregnancy, the plasma triglycerides and cholesterol increase, and that enhanced lipolytic activity plays a pivotal role in making 
free fatty acids available to fetus. ${ }^{5}$ The elevated circulating levels of triglycerides and cholesterol influence was not studied extensively. They are the markers for enhanced preterm risk of labor in pregnant women. This study was conducted to evaluate the elevated triglycerides and cholesterol relationship on preterm labor risk.

\section{METHODS}

350 healthy pregnant women were included in the study group in the age group of 18-36 years, their gestational age was confirmed either by last menstrual period or by ultrasound. Patients who were having pregnancy induced hypertension $(\mathrm{PIH})$, previous preterm delivery, multiple pregnancy, hydromnias, incompetence of cervix were excluded from the study. This study was conducted in Department of Obstetrics and Gynaecology at Osmania University, Hyderabad, Telangana India. A detailed history of diet, habits, followed by complete obstetric and general examination were done in all antenatal mothers. Informed consent form was taken from each and every patient. All antenatal mothers were subjected for serum triglycerides and cholesterol estimation from the overnight fasting blood samples and were included in the study. The blood samples were collected from the overnight fasting at 24,28 and 32 gestation weeks. Total serum cholesterol and serum triglycerides were estimated.

\section{RESULTS}

A master chart was maintained for recording all the information collected regarding all the cases selected. Using Chi-square test, the significance of difference between quantitative variables were determined. A p value less than 0.05 was considered significant. In this study, a total of 300 pregnant women were selected. Table 1 shows that the maximum pregnant women were within the age group of 20-24 years and the mean age was $22.87 \pm 2.89$ years.

Table 1: Demographic distribution of patients.

\begin{tabular}{|l|l|l|}
\hline Age group & No. of cases & $\%$ \\
\hline Less than 20 years & 22 & 7.4 \\
\hline 20-24 years & 220 & 73.3 \\
\hline 25-29 years & 58 & 19.3 \\
\hline Trimester at time of blood cases & No. of cases & $\%$ \\
\hline $2^{\text {nd }}$ trimester & 258 & 86 \\
\hline $3^{\text {rd }}$ trimester & 42 & 14 \\
\hline Gestational age & No. of cases & $\%$ \\
\hline 24 weeks & 200 & 66.6 \\
\hline 28 weeks & 70 & 23.4 \\
\hline 32 weeks & 30 & 10 \\
\hline
\end{tabular}

The assessment of lipids were done on 258 mothers in second trimester and on 42 mothers in third trimester. The gestational age of 24 weeks had the highest number of cases of 200 patients. Table 2 shows that $18(6 \%)$ mothers had abnormal total cholesterol levels in the second trimester and in the 3rd trimester, 7 (2.4\%) mothers had abnormal cholesterol levels. Mean serum cholesterol level was $235.8 \pm 40.9 \mathrm{mg} / \mathrm{dl} 36$ (12\%) mothers had abnormal serum triglycerides in the second trimester and in the 3rd trimester, 7 (2.4\%) mothers had abnormal serum triglycerides. Mean serum cholesterol level was $270.2 \pm 85.4 \mathrm{mg} / \mathrm{dl}$.

Table 2: Estimation of total cholesterol levels, serum triglycerides.

\begin{tabular}{|l|l|l|l|l|}
\hline \multirow{2}{*}{ Trimester } & Notal cholesterol levels (mg/dl) \\
\cline { 2 - 5 } & No. & $\%$ & No. & $\%$ \\
\hline $2^{\text {nd }}$ trimester (258) & 240 & $80 \%$ & 18 & $6 \%$ \\
\hline $3^{\text {rd }}$ trimester (42) & 35 & $11.6 \%$ & 7 & $2.4 \%$ \\
\hline Total (300) & 275 & $91.6 \%$ & 25 & $8.4 \%$ \\
\hline \multirow{2}{*}{ Trimester } & Serum triglycerides levels (mg/dl) \\
\hline & Normal & \multicolumn{3}{|l|}{ Abnormal } \\
\hline $2^{\text {nd }}$ trimester (258) & No. & $\%$ & No. & $\%$ \\
\hline $3^{\text {rd }}$ trimester (42) & 322 & $74 \%$ & 36 & $12 \%$ \\
\hline Total (300) & 257 & $11.6 \%$ & 7 & $2.4 \%$ \\
\hline & & $85.6 \%$ & 43 & $14.4 \%$ \\
\hline
\end{tabular}

Table 3: Serum cholesterol and serum triglycerides and pregnancy outcomes.

\begin{tabular}{|l|l|l|l|l|}
\hline \multirow{2}{*}{ Serum cholesterol } & \multicolumn{3}{|c|}{ Outcome of delivery } \\
\hline & Good & \multicolumn{3}{c|}{ Preterm } \\
\hline No. & $\%$ & No. & $\%$ \\
\hline Normal (272) & 272 & 100 & - & - \\
\hline Abnormal (28) & 19 & 67.9 & 9 & 32.14 \\
\hline \multirow{2}{*}{ Serum triglycerides } & Outcomes of delivery \\
\hline & Good & \multicolumn{4}{|l|}{ Preterm } \\
\hline Normal (260) & No. & $\%$ & No. & $\%$ \\
\hline Abnormal (40) & 259 & 99.62 & 1 & 0.3 \\
\hline & 10 & 25 & 30 & 75 \\
\hline
\end{tabular}

Table 3 shows that the good outcomes were observed in mothers with normal cholesterol values and preterm deliveries were observed in $32.14 \%$ of mothers with abnormal cholesterol values. $0.3 \%$ of mothers with normal triglyceride values and $75 \%$ of mothers with abnormal values had preterm delivery. $\mathrm{P}$ value difference was statistically significant $(\mathrm{P}<0.05)$.

Table 4: Obstetric index and outcome of delivery.

\begin{tabular}{|l|l|l|l|l|}
\hline \multirow{2}{*}{ Obstetric index } & \multicolumn{3}{c}{ Outcome of delivery } \\
\hline & Nerm & \multicolumn{3}{c|}{ Preterm } \\
\hline No. & $\%$ & No. & $\%$ \\
\hline Primigravida (110) & 98 & 89.09 & 12 & 10.9 \\
\hline Multigravida (190) & 179 & 94.21 & 11 & 6.15 \\
\hline
\end{tabular}

Table 4 shows that there was no statistically significant difference between the percentage of preterm deliveries among primigravid mothers and multigravid mothers (0.5574). Table 5 shows that the mean children fetal 
weight at term delivery was significantly higher than that of preterm delivery $(\mathrm{P}<0.05)$.

Table 5: Fetal weight and outcome of delivery.

\begin{tabular}{|l|l|}
\hline Outcome of delivery & Fetal weight $(\mathrm{kg})$ \\
\hline Term delivery & $2.51 \pm 1.17$ \\
\hline Preterm delivery & $1.90 \pm 0.11$ \\
\hline
\end{tabular}

\section{DISCUSSION}

Premature infant is the most important outcome of preterm delivery and is also the cause for infant mortality after congenital abnormality. Around the world, there are 3.6 million per year neonatal deaths, of which in developing countries, $99 \%$ deaths are observed. In pregnancy, maternal hyperlipidemia is common and consistent metabolic alteration. A $25 \%$ to $50 \%$ increase in plasma cholesterol and $150 \%$ to $300 \%$ increase in serum triglycerides is observed. Hyperlipidemia in pregnancy induces atherosis of the utero-placental spiral arteries. Thrombosis and placental infarctions are resulted by atherosis of vital placental arteries combined with hypercoagulation which also may lead to placental insufficiency and fetal compromise. Preterm delivery is the form of fetal compromise. Kramer et al conducted a study in which the risk of spontaneous preterm birth [adjusted odds ratios $(\mathrm{OR}) \mathrm{s}=1.9(95 \% 1.1-3.3)$ and 0.5 (0.3-0.9), respectively] were independently and significantly associated with high (above the median) plasma homocysteine and HDL cholesterol. ${ }^{6}$ Decidual vasculopathy was observed in a higher proportion of women with high homocysteine concentrations [(13.0 vs $6.8 \% ;$ OR $=1.9(1.1-3.5)]$, although the positive association between decidual vasculopathy and preterm birth did not achieve statistical significance [OR $=1.5$ (0.9-2.7)]. No significant associations were observed with the DNA polymorphisms or with plasma TAT or folate levels. Alleman et al reported that even after controlling maternal characteristics, serum screening markers remained significant predictors of PTB. $^{7}$ The best predictive model included maternal characteristics, firsttrimester total cholesterol, total cholesterol change between trimesters, and second-trimester alphafetoprotein and inhibin A. The model showed better discriminatory ability than PTB history alone and performed similarly in subgroups of women without past PTB. Catov et al conducted a study in which high cholesterol or triglycerides <or=15 weeks were associated with a 2.8-fold (1.0-7.9) and 2.0-fold (1.0-3.9) increased risk for preterm birth $<34$ weeks and $>$ or $=34-<37$ weeks, respectively. ${ }^{8}$ Overweight women who delivered <34 weeks had particularly elevated early pregnancy concentrations of cholesterol and low-density lipoprotein; lean women with moderate preterm birth had elevated triglycerides. There was a reduced triglyceride response in the first half of pregnancy among women who delivered $<34$ weeks. Amundsen et al reported that serum lipids increase during pregnancy. However, data are scarce for lipid changes in pregnant women with heterozygous familiar hypercholesterolemia (FH). ${ }^{9}$ The purpose of the present study was to examine plasma lipids and lipoproteins during pregnancy in women with FH. In 22 pregnant women blood samples were collected at gestational weeks 17-20 (baseline), 24, 30 and 36.Total- and LDL cholesterol increased significantly between baseline and gestational week 36 by $29 \%$ and $30 \%$, respectively, compared to $25 \%$ and $34 \%$ in a reference group of 149 healthy pregnant women. Notably, the plasma lipid concentrations in the $\mathrm{FH}$ women were much higher than in the reference women. Triglycerides increased $(\mathrm{P}<0.05)$ by $116 \%$ and $103 \%$, in the FH group and reference group, respectively. HDL cholesterol was unchanged in both groups. Moreover, apolipoprotein B increased significantly during pregnancy in the FH women, whereas apolipoprotein A1 and lipoprotein (a) were unchanged. Pregnancy outcomes in the FH group did not differ significantly from those in the reference group. In conclusion, the relative increase in plasma lipids was similar in pregnant women with $\mathrm{FH}$ and in healthy women, but the absolute magnitude was considerably larger in pregnant FH women. Sowmiya S et al conducted a study in which it was concluded that for predicting the preterm labor, the measurement of serum total cholesterol and triglycerides along with other measures like clinical and serum screening of Alpha fetoprotein and inhibin A can potentially be used. ${ }^{10}$

\section{CONCLUSION}

By measuring serum total cholesterol and triglycerides, along with serum screening of $\alpha$-fetoprotein and inhibin A, it can be used to predict the preterm labour.

\section{Funding: No funding sources \\ Conflict of interest: None declared}

Ethical approval: The study was approved by the Institutional Ethics Committee

\section{REFERENCES}

1. Rafael TJ, Hoffman MK, Leiby BE, Berghella V. Gestational age of previous twin preterm birth as a predictor for subsequent singleton preterm birth. Am J Obstet Gynecol. 2012;206(2):156-e1.

2. Butler AS, Behrman RE, editors. Preterm birth: causes, consequences, and prevention. National Academies Press; 2007.

3. Lawn JE, Kerber K, Enweronu-Laryea C, Cousens S.3.6 million neonatal deaths - what is progressing and what is not? Semin Perinatol. 2010;34(6):37186.

4. Herrera E, Amusquivar E, Lopez-Soldado I, Ortega H. Maternal lipid metabolism and placental lipid transfer. Horm Res. 2006;65(3):59-64.

5. Martin U, Davies C, Hayavi S, Hartland A, Dunne F. Is normal pregnancy atherogenic? Clin Sci. 1999;96(4):421-5.

6. Kramer MS, Kahn SR, Rozen R, Evans R, Platt RW, Chen MF, et al. Vasculopathic and thrombophilic 
risk factors for spontaneous preterm birth. Int $\mathbf{J}$ Epidemiol. 2009;38(3):715-23.

7. Alleman BW, Smith AR, Byers HM, Bedell B, Ryckman KK, Murray JC, et al. A proposed method to predict preterm birth using clinical data, standard maternal serum screening, and cholesterol. Am J Obstet Gynecol. 2013;208(6):472.e1-11.

8. Catov JM, Bodnar LM, Kip KE, Hubel C, Ness RB, Harger G, et al. Early pregnancy lipid concentrations and spontaneous preterm birth. Am J Obstet Gynecol. 2007;197(6):610.e1-7.

9. Amundsen AL, Khoury J, Iversen PO, Bergei C, Ose $\mathrm{L}$, Tonstad S, et al. Marked changes in plasma lipids and lipoproteins during pregnancy in women with familial hypercholesterolemia. Atheroscler. 2006;189(2):451-7.

10. Sowmiya S, Hiremath PB, Kousalya M. Association of hyperlipidemia in preterm delivery. Int $\mathrm{J}$ Reprod Contracept Obstet Gynecol. 2015;4(4):972-6.

Cite this article as: Kundoor R, Rani BS.

Association of hyperlipidaemia in preterm delivery.

Int J Reprod Contracept Obstet Gynecol 2019;8:1637-40. 